\title{
TRASPLANTE DE CÓRNEA: ASPECTOS BIOÉTICOS
}

\author{
Mercedes Hurtado-Sarrió1, Mercedes Duch-Hurtado², Julio Tudela ${ }^{3}$
}

Resumen: Este trabajo aborda los aspectos bioéticos del trasplante de córnea, desde la donación y los tipos de la misma, incluyendo el comercio de órganos y tejidos, así como la metodología del trasplante y el uso de tratamientos inmunosupresores, además del consentimiento informado y la participación del paciente en las decisiones. Se analizan las técnicas actuales, la efectividad y las circunstancias en las que se puede aplicar cada una de ellas así como los estudios emergentes basados en la terapia celular. Algunos de los estudios emplean células troncales derivadas de embriones humanos, y otras de tejidos adultos y células troncales pluripotentes inducidas (iPS). Se propone un análisis bioético de las consecuencias que pueden derivarse de las distintas opciones clínicas disponibles. Por último, se valora en qué medida el paciente participa como actor en su proceso de tratamiento, y la información de que dispone acerca de su enfermedad y del tratamiento que está recibiendo. El paciente debe ser parte activa en su proceso de curación y debe existir un proceso deliberativo en el que sea guiado por el personal facultativo en la elección de su tratamiento, teniendo en cuenta los principios éticos del paciente y del personal sanitario.

Palabras clave: bioética, trasplante de córnea, queratoplastia, donación, inmunosupresión

\section{Corneal transplant: bioethical aspects}

\begin{abstract}
This paper addresses the bioethical aspects of corneal transplantation, from donation and types of donation, including the trade of organs and tissues, as well as the methodology of transplantation and use of immunosuppressive treatments, in addition to informed consent and patient participation. in decisions. The current techniques are analyzed, the effectiveness and the circumstances in which each of them can be applied as well as the emergent studies based on cell therapy. Some of the studies use stem cells derived from human embryos, and others from adult tissues and induced pluripotent stem cells (iPS). A bioethical analysis of the consequences may arise from the different clinical options available. A bioethical analysis of the consequences that can be derived from the different clinical options available is proposed. Finally, it is assessed to what extent the patient participates as an actor in their treatment process, and the information they have about their illness and the treatment they are receiving. The patient must be an active part in his healing process and there must be a deliberative process in which he is guided by the medical staff in the choice of his treatment, taking into account the ethical principles of the patient and the health personnel.
\end{abstract}

Keywords: bioethics, corneal transplant, keratoplasty, donation, immunosuppression

\section{Trasplante de córnea: aspectos bioéticos}

Resumo: Este trabalho aborda os aspectos bioéticos do transplante de córnea como a doação e os tipos da mesma (incluindo o comércio de órgãos e tecidos), a metodologia do transplante e uso de tratamentos imunossupressores, além do consentimento informado e a participação do paciente nas decisóes. Analisam-se as técnicas atuais, a efetividade e as circunstancias nas quais se pode aplicar cada uma delas, assim como os estudos emergentes baseados na terapia celular. Se propóe uma análise bioética das consequências que podem ser derivadas das distintas opçóes clínicas disponíveis. Por último, se avalia em que medida o paciente participa como ator em seu processo de tratamento e a informaçáo de que dispóe sobre sua doença e do tratamento que está recebendo. O paciente deve ser parte ativa em seu processo de cura e ser orientado pela equipe médica no processo deliberativo da eleiçáo de seu tratamento, tendo em conta os princípios éticos do paciente e do pessoal de saúde.

Palavras chave: bioética, trasplante de córnea, ceratoplastia, doação, imunossupressão

\footnotetext{
${ }^{1}$ Universidad de Valencia. Colegio Oficial de Médicos de Valencia (ICOMV), España

${ }^{2}$ Facultad de Medicina de la Universidad Católica de Valencia, España

${ }^{3}$ Instituto de Ciencias de la Vida de la Universidad Católica de Valencia, España.

Correspondencia: julio.tudela@ucv.es
} 


\section{Introducción}

Es comprensible que resulte difícil aceptar, tanto en el entorno de pacientes y familiares como entre los profesionales relacionados con la donación y los trasplantes, que los beneficios de estos tratamientos no lleguen a todos los que lo necesitan y sin demora. En este sentido, las estrategias para aumentar el número de extracciones con órganos válidos pasan obligatoriamente por optimizar la donación. Para ello es necesario alcanzar la detección de todos los posibles donantes en unidades de urgencia y cuidados intensivos, y disminuir las pérdidas de donantes debido a entrevistas familiares con resultado negativo(1). Para conseguir estos objetivos es necesario el apoyo del público y de los profesionales sanitarios, pilares ambos — sociedad y sanidad - imprescindibles para alcanzar la suficiente confianza, elemento clave para favorecer un entendimiento óptimo y una mejor aceptación de la donación en los hospitales autorizados.

En España, líder mundial de trasplantes, la Organización Nacional de Trasplantes comienza desde 2008 el desarrollo del Plan Nacional 40, cuyo objetivo es mejorar las tasas de donación de órganos en nuestro país, cosa que se consigue en gran parte con la llamada donación en asistolia "non beating donor" o donación intermedia entre el donante vivo y en muerte encefálica.

Para implementar el desarrollo de esta donación en asistolia, tanto de pacientes fallecidos en parada cardíaca irrecuperable, como en pacientes a los que se aplica la limitación del tratamiento de soporte vital (LTSV), ha sido necesario adaptarla al Real Decreto 1723/2012, de 28 de diciembre y publicado en el BOE el 29/12/2012, que regula las actividades de obtención y utilización clínica de órganos humanos y la coordinación territorial en materia de donación y trasplante de órganos y tejidos, incluyendo el protocolo de diagnóstico de muerte por parada cardiorrespiratoria y también las condiciones y requisitos para la extracción de órganos de fallecidos por dicho motivo.

\section{Donación en muerte encefálica (ME)}

Un gran avance en la donación de órganos y tejidos se produjo sobre los años 50 del pasado siglo, cuando los médicos franceses describen la mal llamada "muerte cerebral" (muerte solo hay una y cuando uno está muerto, lo está a todos los efectos). Cuando se produce la destrucción del sistema nervioso central, por un traumatismo o una hemorragia, la persona muere. Pero si esa persona está conectada a un respirador y se dan las circunstancias oportunas (un 2\% de los fallecidos en un hospital, entre 4.000 y 5.000 al año en España) va a estar igualmente muerta, pero con el corazón latiendo y bombeando sangre a todos los órganos, manteniéndolos funcionantes unas horas, lo que hace posible la donación de los órganos y tejidos(2)

\section{Donación en asistolia}

Se trata de "la utilización para el trasplante de órganos y tejidos de donantes a corazón parado, es decir, de aquellas personas que fallecen por parada cardiocirculatoria irreversible y que cumplen los requisitos generales de los donantes".

En 1995, en Maastricht, Holanda, se realizó囚 la primera reunión internacional cuyo propósito fue establecer criterios para clasificar a los posibles donantes a corazón parado y así冈 incrementar el número de órganos para trasplante. El resultado de esta reunión fue una clasificación de cuatro categorías: categoría I, individuos que ingresan muertos en urgencias; categoría II, personas que requieren reanimación en el momento de su ingreso, generalmente en urgencias, pero que no resulta efectiva; categoría III, pacientes previamente hospitalizados con parada cardíaca inminente, y categoría IV, pacientes que se encuentran en proceso de diagnóstico de muerte cerebral y presentan parada cardíaca; estos generalmente se localizan en la Unidad de Cuidados Intensivos (UCI) (3).

\section{Donación de córneas}

Los criterios de selección de los donantes son: edad $>2$ años $\mathrm{y}<79$ años, causa de muerte conocida y tiempo de fallecimiento $<2 \mathrm{~h}$. Asimismo, los criterios de exclusión son: edad $<2$ años y $>$ 79 años, enfermedad neoplásica, infección activa sistémica, lesión corneal y cirugía ocular previa.

El procedimiento incluye las siguientes etapas: 
1) extracción de sangre, 2) protección de los ojos con suero fisiológico y oclusión, 3) el médico de guardia y el oftalmólogo valoran al donante y se solicita el consentimiento familiar, 4) preparación del material, 5) preparación del campo quirúrgico, 6) cumplimentación del protocolo, y 7) aviso a la coordinadora de trasplantes.

\section{Comercio de órganos y tejidos. Turismo o viajes de trasplantes. Mercado de órganos y tejidos}

La oferta de órganos no sigue el mismo ritmo que la demanda, la cual va en aumento. La brecha entre el número de donaciones y la lista de espera es cada vez más grande. Se estima que se realizan unos 100.000 trasplantes de órganos al año, de los cuales 5.000 a 8.000 son fruto del comercio.

El tráfico de órganos es el reclutamiento, transporte, traslado, encubrimiento o recepción de órganos procedentes de donantes vivos o de cadáveres por medio de la amenaza, el uso de la fuerza u otras formas de coerción, el secuestro, el fraude, el engaño, el abuso de poder y/o de posición en condiciones de vulnerabilidad, así como la entrega o recepción, a través de terceros, de pagos o beneficios para obtener el control sobre el donante potencial, con el propósito de lograr la extracción de órganos para trasplante por medio de la explotación. Es una política o práctica en la que un órgano se considera una mercancía que se puede comprar, vender o utilizar con el fin de obtener ganancias materiales.

Por todos los problemas cada vez mayores de turismo de trasplantes y tráfico de los donantes de órganos ante la escasez mundial de los mismos, en 2008 se hizo pública la Declaración de Estambul, con el consenso de los participantes, los cuales fueron seleccionados de acuerdo a las siguientes consideraciones: vínculos del país con la Sociedad de Trasplantes, que representa prácticamente a todos los países con programas de trasplantes; representantes de sociedades internacionales y el Vaticano; personas con cargos directivos en nefrología y trasplantes; participantes en el ámbito de políticas públicas de trasplante de órganos y eticistas, antropólogos, sociólogos y especialistas en cuestiones jurídicas de prestigio, por sus publicaciones sobre la política y la práctica de los trasplantes(4). La declaración insta a todos los países a aplicar los marcos legales y profesionales que regulen la obtención de órganos de donantes cadáver, y a llevar a cabo la práctica de los trasplantes de manera que sea compatible con las normas internacionales.

\section{La terapia celular. Cultivos celulares, órganos bioproducidos, IPS y transdiferenciación celular}

Para tratar de resolver la escasez de órganos para ser trasplantados(5), además de los trasplantes totales o parciales de córnea (trasplantes endoteliales, en el caso de descompensación endotelial, o lamelares anteriores, en caso de afectación de capas externas de la córnea), que dependen de la donación de córneas y presentan problemas de compatibilidad, surgen alternativas como la producción de córneas bioartificiales, con cultivos de células endoteliales (en experimentación) y la fabricación de córneas con materiales compatibles con el ojo que permitan su implantación: la llamada córnea artificial, de la cual existe un modelo en el mercado: la queratoprótesis de Boston.

El cultivo de células endoteliales, consiste en la obtención de una muestra del endotelio descompensado del paciente, mediante una pequeña biopsia de la periferia corneal, usando como vehiculizador la propia membrana de Descemet, y la eliminación de las células endoteliales deterioradas, dejando las viables que serían cultivadas sobre la membrana de Descemet hasta conseguir una monocapa de células endoteliales que podría trasplantarse al paciente según una técnica ya utilizada para trasplantes endoteliales con ojos de donantes. Se lograría de este modo un trasplante autólogo de la capa endotelial dañada con células cultivadas del propio paciente, evitando depender de donaciones y los problemas de compatibilidad e inmunosupresiones.

En estudios experimentales, ya se ha podido cultivar monocapas de células endoteliales a partir de los rodetes corneo-esclerales desechados tras realizar la queratoplastia penetrante del botón corneal central $(6,7)$. Incluso algunos ensayos han conseguido reproducir las capas de la córnea en animales $(8,9)$.

La Queratoprótesis de Boston (fig. 1) consiste en la implantación de una prótesis en pacientes con alto riesgo de rechazo. El diseño integra ma- 
teriales sintéticos biocompatibles, como el polimetilmetacrilato (PMMA)(10). Son por lo tanto mal llamadas "artificiales", pues solo una parte es artificial y se combina con una córnea de donante(11).

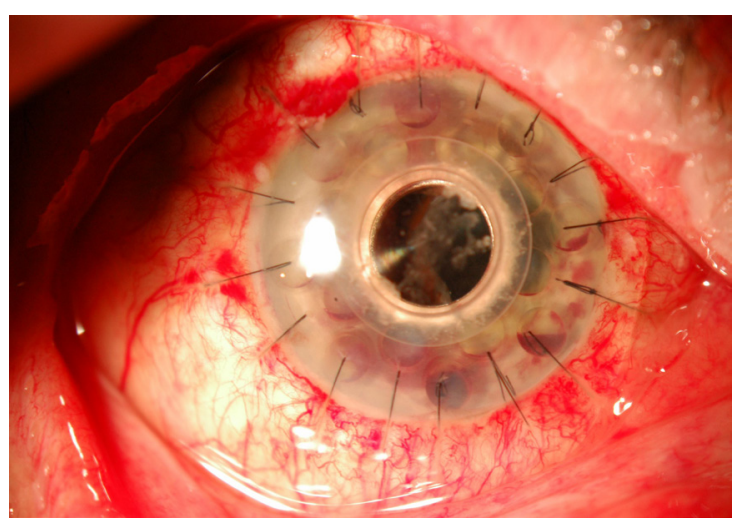

Fig. 1: Queratoprótesis de Boston. (Imagen propia).

Las complicaciones más frecuentes son la formación de membranas retroprotésicas, glaucoma e infecciones. También son frecuentes las extrusiones, por lo cual se reservan para casos límite en los que han fracasado los procedimientos habituales.

Por último, se debe mencionar los estudios que están siendo dirigidos a conseguir células pluripotenciales, que puedan dar lugar a órganos y tejidos(12). En oftalmología, ya se han realizado ensayos en animales y humanos con trasplante de células del epitelio pigmentario retiniano, para el tratamiento de la degeneración macular asociada a la edad(13), aunque no han sido utilizadas en el trasplante de córnea. Estas células troncales pueden obtenerse a partir de células embrionarias o adultas(14). Las células troncales embrionarias se obtienen de embriones sobrantes de fecundaciones in vitro (FIV), aunque también pueden ser producidas por transferencia nuclear somática o generados por partenogénesis. La utilización de células troncales embrionarias, tanto para fines experimentales como hipotéticamente terapéuticos, han sido y son objeto de uno de los más apasionados debates de los últimos años en el campo de la bioética, dado que para obtenerlas hay que ineludiblemente destruir embriones hu$\operatorname{manos}(15,16)$.
Las células troncales adultas o somáticas tienen restringida su capacidad de diferenciación. En los últimos años han tomado interés las células troncales mesenquimales, aisladas del tejido adiposo dada su plasticidad de desarrollo y su potencial terapéutico. Su procedencia es autóloga, de sangre periférica o tejido adiposo, y su uso no presenta trastornos inmunológicos ni problemas éticos.

A partir de los primeros experimentos de Takahashi y Yamanaka(17), las células troncales pluripotentes inducidas o IPS han revolucionado la biología de las células troncales y sus posibles aplicaciones terapéuticas en medicina regenerati$\mathrm{va}(18)$. Los investigadores japoneses demostraron que, al añadir un reducido número de genes, se posibilitaba la transformación y la inducción de células somáticas a células troncales pluripotentes. Como tales, estas células podrían formar órganos y tejidos, y entre ellos el de la córnea.

Los nuevos avances sobre la reprogramación celular, y especialmente la consecución de las células iPS, han significado una esperanzadora posibilidad para no tener que utilizar en la investigación experimental y en la clínica médica células embrionarias humanas, ya que, por requerir para su obtención la destrucción de embriones humanos, su uso no es éticamente aceptable(19).

El problema de estas células sigue siendo la posibilidad de inducir la formación de tumores, y el uso de vectores víricos para introducir los factores reprogramados que podría favorecer el desarrollo de enfermedades víricas $(15,18,20)$. Para evitar estos problemas se siguió investigando y se consiguió la reprogramación directa de células somáticas adultas en otro tipo celular, sin pasar por el estado de pluripotencialidad propio de las células iPS. Esto es la "transdiferenciacion celular", procedimiento que no tiene dificultades éticas, dado que mejora el método tradicional para conseguir células iPS y podría desarrollar terapias específicas para pacientes concretos; aunque no hay resultados en esta línea de investigación, ni en mamíferos ni en seres humanos, los resultados obtenidos hasta el momento son muy esperanzadores para algunos autores(21). Aunque otros consideran que, aun siendo fenotípicamente equiparables a las embrionarias, las iPS muestran perfiles de expresión genética diferentes, distinta capacidad de 
proliferación y diferenciación, y pueden mantener una "memoria genética del tejido adulto del que proceden" (22).

\section{Material y método}

Se realiza un estudio descriptivo observacional con datos obtenidos del Servicio de Oftalmología del Hospital Universitario y Politécnico de La Fe de Valencia, del periodo 2010-2018, con el fin de estudiar el conocimiento que tienen los pacientes de su patología, en qué medida forman parte de la toma de decisiones en su proceso patológico, y si el médico es parte activa en la toma de decisiones ayudando en el proceso deliberativo, teniendo en cuenta los principios éticos tanto del médico como del paciente. Para ello, se ha elaborado una encuesta (anexo 1) que han contestado los pacientes. Las preguntas han sido leídas por ellos mismos o con la ayuda de un acompañante. Incluye 56 pacientes sometidos a trasplante de córnea en los meses de enero de 2017 a marzo de 2018, que han contestado la encuesta en la consulta de Oftalmología del Hospital Universitario y Politécnico La Fe de Valencia (España), cuando acudían llamados para un trasplante de córnea por la existencia de una donación compatible, al tiempo que firmaban el consentimiento informado.

\section{Resultados}

\section{Inmunosupresión en el trasplante córnea}

Cuando se precisa de un tratamiento inmunosupresor sistémico por el alto riesgo de rechazo, en nuestro Servicio se utiliza el micofenolato de mofetilo desde 2010, como alternativa a la ciclosporina $\mathrm{A}$, que usábamos clásicamente.

Cuando usábamos la ciclosporina existía gran número de efectos secundarios, sobre todo nefrotoxicidad e hipertensión, así como la aparición de neoplasias, por lo que se precisaba un estrecho seguimiento junto con especialistas de medicina interna. Utilizando el micofenolato de mofetilo los efectos secundarios se reducen a alteraciones gastrointestinales que normalmente ceden tras los primeros meses de tratamiento. En nuestra experiencia con una media de 50 trasplantes corneales al año, a) es bien tolerado y disminuye el número de episodios de rechazo en las queratoplastias de alto riesgo; b) tenemos casos de injertos transparentes a los 2 años que habían sufrido 3 y 4 retrasplantes fracasados; c) es efectivo en el rescate de episodios de rechazo, asociándolo a corticoides tópicos y perioculares; d) en caso de efectos secundarios, éstos disminuyen o desaparecen al bajar la dosis de 2 gramos/día a 1 gramos/día; e) vigilamos estrechamente al paciente para evitar infecciones intercurrentes graves, habiendo detectado 4 casos de 120 en los últimos 3 años en nuestro Servicio; f) somos cautos al disminuir la dosis, pues pueden aparecer episodios de rechazo virulentos.

Según nuestra experiencia, por tanto, el micofenolato de mofetilo (MMF) supone una alternativa a otros agentes inmunosupresores como la ciclosporina, con menos efectos secundarios sistémicos y que reduce la probabilidad de rechazo a un $77,72 \%$, principalmente en los casos de alto riesgo.

Aunque se trata de un fármaco con alto coste y sujeto a rigurosos controles de prescripción, tanto su mayor eficacia como sus menores efectos secundarios lo sitúan actualmente como la mejor alternativa terapéutica, si se evita anteponer criterios economicistas a la salud de nuestros pacientes.

\section{Trasplante}

Las córneas empleadas en los trasplantes proceden de donaciones a corazón parado (en asistolia) de nuestro propio hospital en la mayoría de los casos, aunque un $5 \%$ proceden de otros hospitales.

En el Hospital Universitario y Politécnico La Fe se puso en marcha en 2010 un protocolo de donación de órganos y tejidos en pacientes a los que se realizaba una LTSV, en colaboración con el Instituto de Hepatología Experimental y la Unidad de Neonatología, encaminado a la obtención de hígados para aislar hepatocitos, injertos valvulares cardiacos y córneas, y en 2011 un programa de donación en asistolia con pacientes Maastricht tipo I y II, en colaboración con el SAMU de Valencia. Esto ha aumentado considerablemente el número de donaciones. La LTSV, como limitación del esfuerzo terapéutico, evita la obstinación terapéutica y facilita que otras personas se puedan 
beneficiar con las donaciones; por lo tanto, de acuerdo con los principios bioéticos.

En cuanto a la promoción de la donación, modelos, selección de córneas y técnicas de implante, en el Servicio de Oftalmología del Hospital Universitario y Politécnico La Fe seguimos el Plan Nacional de Córneas aprobado por la Comisión Nacional de Trasplantes del 15 de junio de 2016, con la ONT y el Ministerio de Sanidad, Servicios Sociales e igualdad, sometidos a comités bioéticos para su aprobación.

Se han publicado ensayos con células troncales en animales, pero no en humanos, como ocurre con la patología retiniana, más avanzada en este sentido. Cuando se trasladen estos ensayos a humanos, aplicados al trasplante de córnea, probablemente se abrirá un debate ético, al cual deberemos estar atentos para que se respeten las normas bioéticas.

\section{El paciente como actor en su proceso de trata- miento}

La mayoría de los 56 pacientes que han participado en el estudio han sido mujeres $(58,9 \%)$ frente al $41,1 \%$ de varones (figura 2). La explicación a esto es, probablemente, la mayor esperanza de vida de las mujeres en nuestro medio.

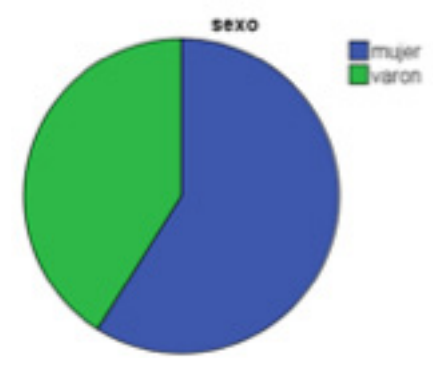

Fig. 2. Distribución del grupo de estudio según sexo.

En cuanto a la edad se recoge en la figura 3, y sigue una distribución normal. La edad media del grupo de pacientes estudiados es de 73,55 años (desviación típica 10,696). El 69,6\% no sabe leer ni escribir o su nivel de estudios es básico. Solo 9 de los pacientes tiene estudios de grado medio y 8 estudios superiores. La distribución según el nivel académico aparece en la figura 4.

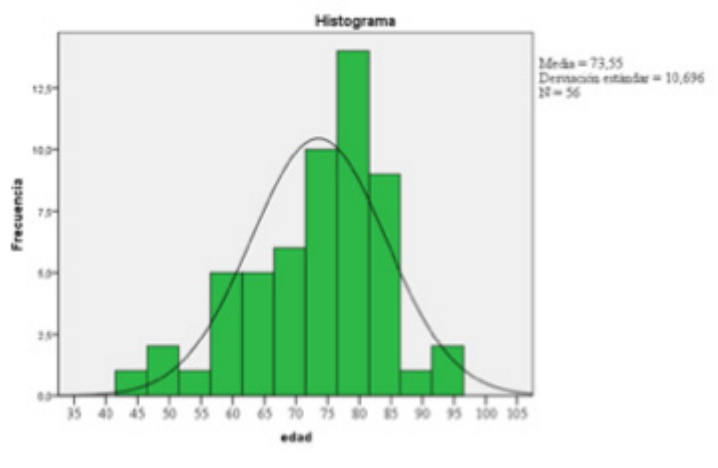

Fig. 3. Distribución por edad del grupo de estudio. La prueba de normalidad de KolmogorovSmirnov tiene un estadístico de 0,09 y un nivel de significación de 0,2.

\begin{tabular}{|c|c|c|}
\hline \multicolumn{2}{|c|}{$\begin{array}{l}\text { Prueba de Kolmogorov-Smirnov para una } \\
\text { muestra }\end{array}$} & Edad \\
\hline \multicolumn{2}{|l|}{$\mathrm{N}$} & 56 \\
\hline \multirow{2}{*}{$\begin{array}{l}\text { Parámetros } \\
\text { normales }^{\mathrm{a}, \mathrm{b}}\end{array}$} & Media & 73,55 \\
\hline & Desviación estándar & 10,696 \\
\hline \multirow{3}{*}{$\begin{array}{l}\text { Máximas diferencias } \\
\text { extremas }\end{array}$} & Absoluta & 0,125 \\
\hline & Positivo & 0,069 \\
\hline & Negativo & $-0,125$ \\
\hline \multicolumn{2}{|l|}{ Estadístico de prueba } & 0,125 \\
\hline \multicolumn{2}{|c|}{ Sig. asintótica (bilateral) } & $0,028^{\mathrm{c}}$ \\
\hline \multicolumn{2}{|c|}{ a. La distribución de prueba es normal. } & \\
\hline \multicolumn{2}{|c|}{ b. Se calcula a partir de datos. } & \\
\hline \multicolumn{2}{|c|}{ c. Corrección de significación de Lilliefors. } & \\
\hline
\end{tabular}

Es una distribución normal $(\mathrm{p}=0,028)$.

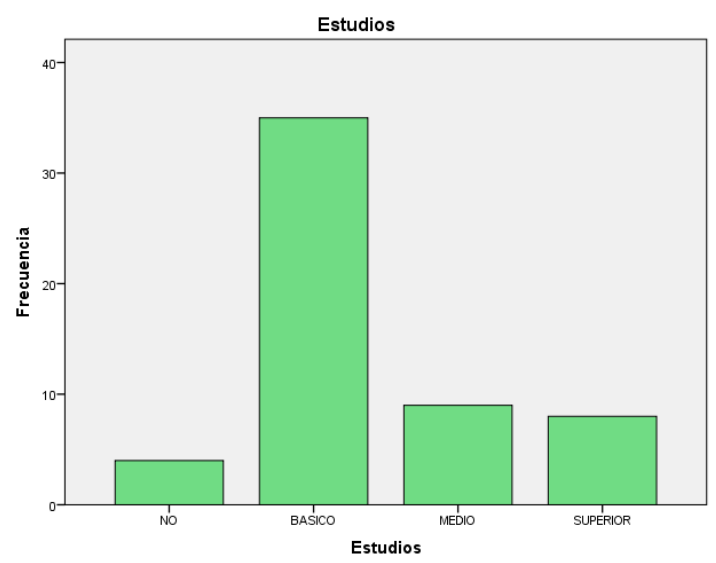

Fig. 4. Distribución del grupo de estudio según su nivel académico. 
No tienen conocimientos acerca de biología ni bioquímica, ni están familiarizados con los términos científicos que empleamos habitualmente. La causa del trasplante ha sido una descompensación corneal endotelial poscirugía de cataratas en la mayoría de los casos, salvo en 4 de ellos en los cuales la etiología eran leucomas corneales postinfección herpética y 1 por leucoma postraumático. En 6 de los casos se trataba de un retrasplante, 1 de ellos tras 2 rechazos previos. Este paciente manifestó que se sometería a un nuevo trasplante hasta que lo dijeran los médicos, e insistió en que él no iba a decidir nada sobre lo que no sabía, y que continuaría el tratamiento siempre que se lo dijera el facultativo.

En cuanto al consentimiento informado, solo 23 de los 56 pacientes lo han leído (tabla 1). Los demás lo han firmado directamente.

\begin{tabular}{|c|c|c|c|}
\hline \multicolumn{2}{|c|}{} & Frecuencia & Porcentaje \\
\hline \multirow{3}{*}{ Válido } & NO & 33 & 58,9 \\
\cline { 2 - 4 } & SÍ & 23 & 41,1 \\
\cline { 2 - 4 } & Total & 56 & 100,0 \\
\hline
\end{tabular}

Tabla 1. Número de pacientes que ha leído o le han leído el consentimiento informado.

A la pregunta de si el paciente conoce si existe otro tratamiento para su enfermedad, todos contestaron que lo desconocían. Uno contestó que esperaba que pronto se pudiese trasplantar el ojo entero.

En cuanto a la pregunta de si se sometería a tratamientos en fase experimental, los pacientes se distribuyen casi en la misma proporción en las tres posibles respuestas (tabla 2). Es llamativo que un $34 \%$ de los casos no se lo haya planteado o no sepa que haría.

\begin{tabular}{|c|l|c|c|}
\hline \multicolumn{2}{|c|}{} & Frecuencia & Porcentaje \\
\hline \multirow{4}{*}{ Válido } & NO & 20 & 35,7 \\
\cline { 2 - 4 } & NO SABE & 14 & 25,0 \\
\cline { 2 - 4 } & SÍ & 22 & 39,3 \\
\cline { 2 - 4 } & Total & 56 & 100,0 \\
\hline
\end{tabular}

Tabla 2. Distribución de los pacientes según la respuesta a la pregunta: ¿se sometería a tratamientos en fase experimental?
Un paso más es preguntar si se someterían a tratamientos que empleen células madre de origen embrionario (tabla 3). Una parte importante de los pacientes no lo haría $(30,5 \%)$ y una parte no despreciable tiene dificultades para entender los términos de la pregunta $(44,6 \%)$.

\begin{tabular}{|c|c|c|c|}
\hline & & Frecuencia & Porcentaje \\
\hline \multirow{4}{*}{ Válido } & $\mathrm{NO}$ & 17 & 30,4 \\
\hline & NO SABE & 25 & 44,6 \\
\hline & SÍ & 14 & 25,0 \\
\hline & Total & 56 & 100,0 \\
\hline
\end{tabular}

Tabla 3. Distribución de los pacientes según si se someterían a tratamientos con células madre embrionarias.

Cuando se les pregunta a los pacientes sobre si preferirían un tratamiento con células madre de origen no embrionario, el grupo más numeroso es el que responde que no lo sabe $(64,3 \%)$ (tabla 4).

\begin{tabular}{|l|l|c|c|}
\hline \multirow{5}{*}{ Válido } & NO & Frecuencia & Porcentaje \\
\cline { 2 - 4 } & NO SABE & 36 & 19,6 \\
\cline { 2 - 4 } & SÍ & 9 & 64,3 \\
\cline { 2 - 4 } & Total & 56 & 16,1 \\
\hline \multirow{3}{*}{} & & 100,0 \\
\hline
\end{tabular}

Tabla 4. Distribución de los pacientes según si preferirían tratamientos con células madre de origen no embrionario.

La distribución de los pacientes según su disposición a someterse a trasplante con células madre de origen embrionario y si preferirían uno con células madre de origen no embrionario ofrece un resultado estadísticamente significativo. El grupo más numeroso es el que contesta "no lo sé" en ambos casos; sin embargo, hay un grupo de pacientes que se sometería al tratamiento si fuera con células madre no embrionarias y no lo harían en caso contrario (tabla 5). 


\begin{tabular}{|c|c|c|c|c|c|}
\hline & \multicolumn{3}{|c|}{$\begin{array}{l}\text { C Madre NO } \\
\text { Embrionaria }\end{array}$} & \multirow[b]{2}{*}{ 焉 } \\
\hline & & $\mathrm{NO}$ & \begin{tabular}{|l} 
NO \\
SABE
\end{tabular} & SÍ & \\
\hline \multirow{3}{*}{$\begin{array}{l}\text { C. Madre. } \\
\text { Embrion. }\end{array}$} & $\mathrm{NO}$ & 6 & 7 & 4 & 17 \\
\hline & NO SABE & 0 & 25 & 0 & 25 \\
\hline & SI & 5 & 4 & 5 & 14 \\
\hline \multicolumn{2}{|l|}{\begin{tabular}{|l} 
Total \\
\end{tabular}} & \begin{tabular}{|l|}
11 \\
\end{tabular} & 36 & 9 & 56 \\
\hline
\end{tabular}

Tabla 5. Análisis estadístico de los pacientes que se someterían a tratamientos con células madre de origen embrionario y si preferirían que fueran de origen no embrionario. (Prueba exacta de Fisher p 0.000).

\section{Discusión}

\section{Aspectos bioéticos del trasplante de córnea}

Según la bioética principialista, la donación de córnea se sustenta en los principios éticos básicos de no maleficencia, beneficencia, autonomía y justicia social: la extracción y trasplante es un procedimiento sin ánimo de lucro, basado en el altruismo de los donantes y sus familias y cuyo fin último es conseguir la salud del individuo, derecho de todos los españoles recogido en la Constitución española y, por tanto, debe considerarse un bien social, lo cual cumple también los requerimientos en este aspecto de la bioética pragmática-utilitarista, que persigue el mayor beneficio para el mayor número de individuos. Pero además es necesario mantener siempre el respeto a la voluntad del difunto, expresada en vida y testificada por sus familiares o representante legal. Se considera fundamental el derecho de la familia a estar informada en todo momento del procedimiento, no ocultando su realización fuera cual fuera la voluntad del difunto o de la familia acerca de la donación. Debe suministrarse, por tanto, información completa e inteligible, siendo responsabilidad de los facultativos que recaban el consentimiento informado asegurarse de que el paciente ha comprendido aquello que consiente o rechaza, tal como exige la bioética personalista.

Igualmente, se considera fundamental el derecho de la familia a ver al difunto y disponer de unos minutos para despedidas antes de iniciar la extracción. El equipo médico que realiza la reanimación y diagnóstico de muerte cardíaca es total- mente independiente de la donación y diferente al equipo que realiza la extracción y el trasplante. No se realiza ningún procedimiento sobre el cadáver hasta que no está certificada la defunción por el médico que llevó a cabo la reanimación o se hace constar en la hoja de evolución. Es decir, el inicio de la perfusión-extracción-trasplante se hace cuando el equipo de reanimación ha dejado constancia escrita de la muerte por parada cardiorrespiratoria y/o encefálica.

A este respecto se plantea un dilema bioético respecto de la certificación de la muerte, que nace del conflicto entre la necesidad de celeridad en la extracción de los órganos que han de trasplantarse, con el fin de que no sufran daños irreversibles que malograrían la intervención, y la necesidad de una certificación correcta del óbito del paciente, de modo que, en ningún caso, pudiera efectuarse la extracción en un paciente todavía vivo. Esta premura viene irremediablemente limitada por la necesidad de cerciorarse de que el paciente donante ha muerto definitivamente. La extracción de un órgano en un paciente agonizante, pero no todavía fallecido, implicaría infringirle un daño o provocarle la muerte, extremo inaceptable éticamente(23). La dificultad surge ante la delimitación precisa de los criterios para establecer la muerte de un paciente con la máxima seguridad. El dilema de utilizar la parada cardiorrespiratoria como criterio para establecer el momento de la muerte, es la capacidad de resucitación y este periodo es objeto de controversia, admitiéndose como suficiente 75 segundos por algunos autores, o hasta 15 minutos por otros(24).

La muerte cerebral se puede establecer por inactividad en el electroencefalograma o por gammagrafía cerebral. Aquí el problema reside en definir la propia muerte cerebral (muerte de los hemisferios cerebrales-muerte del troncoencéfalo). En este sentido, la muerte encefálica global es la que ofrece una mayor certeza(25).

En la muerte encefálica, pero con el corazón latiendo artificialmente, la controversia existe sobre cuándo desconectar al paciente. Esta situación resulta más difícil de entender por parte de los familiares del donante.

En estos momentos se considera necesario evolu- 
cionar hacia la obtención de órganos de pacientes siguiendo los criterios Maastricht tipo III, ya que la LTSV en nuestro hospital se está convirtiendo en práctica frecuente y, además, es una actuación acorde con la buena práctica médica reconocida, constituyendo este segundo tipo de pacientes una opción excelente para la obtención de órganos(3). Actualmente, en la literatura se está imponiendo el término "donación" tras parada circulatoria, o a corazón parado, más exacto quizás que el de donación en asistolia.

En nuestro entorno más próximo esta modalidad de donación ha supuesto un importante incremento de las donaciones. Se cumple en todo momento un protocolo establecido por la Dirección del Hospital con el informe favorable del Comité de Ética hospitalario.

En el caso de donación a corazón parado es más fácil aceptar la muerte por parte de los familiares que en el de muerte encefálica, en el que algunas familias expresan reticencias. En estos casos debe ofrecerse información clara, inteligible y rigurosa con el fin de suscitar la generosidad de los implicados.

En cuanto al ejercicio del derecho de autonomía del paciente, debe puntualizarse que, en nuestra muestra de estudio y como ya se ha apuntado, solo 23 de los 56 pacientes leyeron el documento de consentimiento informado. Los demás lo han firmado directamente. Este extremo puede suponer un menoscabo en el ejercicio de este derecho, que no debe limitarse a rubricar el documento, sino que el facultativo debe procurar asegurarse de que el paciente lo ha entendido en un nivel suficiente como para permitirle una toma de decisión ponderada.

En cuanto al principio de justicia, a pesar del elevado coste del fármaco inmunosupresor que empleamos actualmente (el micofenolato de mofetilo) y de los trámites burocráticos que hay que seguir para su prescripción, su uso está justificado por el beneficio de su empleo y los escasos efectos secundarios comparados con otros fármacos inmunosupresores.

Frente al principio de no comercialización del cuerpo humano, hay quienes, desde posiciona- mientos liberales utilitaristas, defienden la posibilidad de un mercado ético de órganos, esto es, un mercado organizado internacionalmente en el que el vendedor de órganos los suministra al Estado o a una organización internacional que paga un precio "justo" por ellos, evitando así el mercado negro y la explotación. Afirman estos autores que este tipo de mercado es un medio ético para aumentar el número de órganos disponibles $(26,27)$. Quienes se oponen a él argumentan que atenta contra la dignidad humana, es una nueva forma de explotación, más extrema que la propia situación de indigencia y pobreza, tendría un efecto negativo sobre la donación porque disminuiría el número de donantes altruistas y supondría, además, una subversión de los estándares de donación recogidos en la legislación. Existe la necesidad de crear una conciencia solidaria acerca del generoso acto de la donación, porque responde a la desesperada situación de miles de personas en todo el mundo, pues sigue siendo la mayor fuente de esperanza para las personas necesitadas de un trasplante(28).

La experimentación con células troncales embrionarias junto con el tráfico de órganos constituyen los grandes dilemas bioéticos en el trasplante, que en oftalmología ya están afectando a algunas patologías como la degeneración macular asociada a la edad. En el caso del trasplante de córnea, los ensayos se realizan todavía en animales, pero la delimitación de fronteras éticas se hace necesaria para prevenir excesos en el futuro.

\section{El paciente como actor en su proceso de trata- miento}

En cuanto a la relación médico-paciente que nos encontramos en el día a día de los que realizamos trasplantes de córnea, observamos que los pacientes no conocen si hay alternativas terapéuticas para su proceso, distintas de las que se le están aplicando, como se pone de manifiesto en la encuesta realizada en este trabajo. Los pacientes no se han planteado la posibilidad de un tratamiento con células troncales, reconocen desconocer incluso el significado de los términos, aunque les "suena" haber oído cosas en los medios de comunicación. Se trata la mayoría de las veces de pacientes de más de 65 años de edad, pues la causa actual más frecuente de trasplante de córnea es 
la descompensación endotelial poscirugía de cataratas, y esta cirugía normalmente se realiza en pacientes mayores. Ya sea por lo desesperado de la enfermedad o por la confianza del paciente en el equipo sanitario, el paciente no es un sujeto activo en la toma de decisiones sobre el tratamiento de su patología. Es cierto que toma parte, dado que firma el consentimiento informado y recibe información verbal y escrita. Pero es patente que, en muchos casos, el paciente se pone en manos del facultativo, prefiriendo un modelo paternalista.

Debe evitarse en todo caso una justificación utilitarista de la limitación en la información suministrada al paciente basada en el deber de secreto $(29)$.

Un planteamiento subjetivista-relativista concebiría el consentimiento informado como una herramienta de tutela jurídica a la que se acomodan dos voluntades, dos autonomías. Esta concepción del consentimiento por parte del médico implica además una concepción utilitarista del paciente, ya que únicamente se considera relevante en la relación médico-enfermo el que exista la firma del paciente sobre un documento informativo.

\section{Conclusión}

Los resultados de este trabajo ponen de manifiesto que hoy en día el modelo paternalista sigue prevaleciendo en demasiadas ocasiones en la relación médico-paciente. El nivel educativo de los pacientes que en nuestro medio se someten a trasplante de córnea, y su desconocimiento de los medios a nuestro alcance, incluso de la terminología utilizada, hace patente que el desarrollo del principio de autonomía según el modelo principialista, o de libertad-responsabilidad según el personalista, necesita completarse.

Progresar en la comunicación con el paciente, informar con rigor y claridad suficiente a todos los implicados en el proceso, emplear técnicas de inmunosupresión más eficaces y delimitar criterios nítidos acerca de las circunstancias del diagnóstico de muerte y extracción de órganos, además de consensuar criterios éticos en las nuevas posibilidades de terapia celular, se proponen como áreas de mejora en la valoración bioética del trasplante de córnea en la actualidad.

\section{Referencias}

1. González MA, Martínez García JM, Manrique S. Donación de órganos para transplantes. Aspectos psicosociales. Nefrología 1991; 11(1): 62-68.

2. Dominguez-Gil B, Haase-Kromwijk B, Van Leiden H, Neuberger J, Coene L, Morel P, et al. Current situation of donation after circulatory death in European countries. Transplant International 2011; 24(7): 676-686.

3. Rubio-Muñoz JJ, Pérez-Redondo S, Alcántara-Carmona S, et al. Protocolo de donación tras la muerte cardíaca controlada (donante tipo III de Maastricht). Experiencia inicial. Medicina Intensiva 2014; 38(2): 92-98.

4. Gracida-Juárez C, Alberú-Gómez J. El papel global del trasplante renal. Nefrología 2012; 32(1): 1-6.

5. Aznar Lucea J, Tudela Cuenca J, Sánchez García JL. Producción de órganos bioartificiales. Cuadernos de Bioética 2015; 26(1): 149-169.

6. Gutierrez Salinas J, Castillo Vázquez M, Galicia Carreón J, Galicia Tapia J. Historia del trasplante de córneas y los medios para su preservación. Medicina Interna de México 2005; 21(5): 380-385.

7. Li W, Sabater AL, Chen YT, Hayashida Y, Chen SY, He H, et al. A novel method of isolation, preservation, and expansion of human corneal endothelial cells. Investigative Ophthalmology and Visual Science 2007; 48(2): 614-620.

8. Nishida K. Tissue engineering of the cornea. Cornea 2003; 22(7): S28-S34.

9. Alaminos M, Sánchez-Quevedo MdC, Muñoz-Ávila I, Serrano D, Medialdea S, Carreras I, et al. Construction of a complete rabbit cornea substitute using a fibrin-agarose scaffold. Investigative Ophthalmology and Visual Science 2006; 47(8): 3311-3317.

10. Chirila T. An overview of the development of artificial corneas with porous skirts and the use of PHEMA for such application. Biomaterials 2001; 22(24): 3311-3317.

11. Muñoz-Gutierrez G, De Toledo JA, Barraquer RI, Vera L, Valereia RC, Nadal J, et al. Pronóstico visual y complicaciones posquirúricas en queratoprótesis de Boston tipo 1. Archivos de la Sociedad Española de Oftalmología 2013; 88(2): 56-63. 
12. Eiraku M, Takata M, Ishibashi H, Kawada M, Sakakura E, et al. Self-organizing optic-cup morphogenesis in threedimensional culture. Nature 2011; 472(7341): 51-56.

13. Song WK, Park KM, Kim HJ, Lee JH, et al. Treatment of macular degeneration using embrionic stem cell-derived retinal pigment epithelium: preliminary results in Asian patients. Stem Cell Reports 2015; 4(5): 860-872.

14. Jill J. Stem Cell Treatments. JAMA 2017; 317(3): 330.

15. Aznar Lucea J, Martinez M. Reflexión ética alrededor de la reprogramación celular. Cuadernos de Bioética 2012; 23(2): 287-299.

16. Aznar J, Sánchez JL. Embryonic stem cells: are useful in clinic treatments? Journal of Physiology and Biochemistry 2011; 67(1): 141-144.

17. Takahashi K, Yamanaka S. Induction of pluripotent stem cells from mouse embryonic and adult fibroblast cultures by defined factors. Cell 2006; 126(4): 663-676.

18. Aznar J, Tudela J. Ten years since the discovery of iPS cells: The current state of their clinical application. Revista Clinica Española (English Edition) 2017; 217(1): 30-34.

19. Aznar J. From Stem Cells to iPS Cells. A passionate Journey. Studia Bioethica 2009; 2(1): 86-94.

20. Hyun I, Hochedlinger K, Jaenisch R, Yamanaka S. New advances in iPS cell research do not obviate the need for human embryonic stem cells. Cell Stem Cell 2007; 1(4): 367-368.

21. Szabo E, Rampalli S, Risueño RM, Schnerch A, Mitchell R, Fiebig-Comyn A, et al. Direct conversion of human fibroblasts to multilineage blood progenitors. Nature 2010 november; 468(7323): 521-526.

22. Kim K, Doi A, Wen B, et al. Epigenetic memory in induced pluripotent stem cells. Nature 2010; 467(7313): 285-290.

23. Tudela J, Aznar J. Trasplantes de órganos postmortem. Aspectos éticos y médicos. Civica. Asociación de investigadores y profesionales por la vida 2016: febrero.

24. Machado C, Dorein J. Irreversibility: Cardiac death versus brain death. Institute of Neurology and Neurosurgery. Habana Cuba. Rev. Neurosci. 2009; 20(3-4): 199-202.

25. Domínguez Roldán J, Fernández M, Alfaro G, Chacón J. Sonografía Doppler transcraneal: su utilidad en el diagnóstico de la parada circulatoria cerebral que acompaña a la muerte encefálica. Medicina Intensiva 2000; 24(4): 151-60.

26. Richards JR. Commentary. An ethical market in human organs. Journal of Medical Ethics 2003; 29(3): 139-140.

27. Richards JR. Nephrarious Goings On Kidney Sales and Moral Arguments. Journal of Medicine and Philosophy 1996; 21(4): 375-416.

28. Matesanz R, Alvarez-Lara MA, Martín-Malo A, et al. Tráfico de órganos: hechos, ficciones y rumores. Nefrología 1994; 14(6): 633-645.

29. Júdeza J, Nicolás P, Delgado MT, Hernando P, Zarco J, Granollers S. La confidencialidad en la práctica clínica: historia clínica y gestión de la información. Medicina Clínica 2002; 118(1): 18-37.

Recibido: 27 de septiembre de 2018

Aceptado: 5 de noviembre de 2018 